\title{
Indian Construction Industry: Challenges for the Construction Managers
}

\author{
Er. Shrishail Shirur ${ }^{1}$, Dr. Suwarna Torgal ${ }^{2}$ \\ ${ }^{1}$ Project Manager, Power Transmission and Distribition IC, Laresn \& Toubro Construction Ltd, India. \\ ${ }^{2}$ Assistant Professor, Dept of Mechanical Engineering, Institute of Engineering \& Technology, Devi Ahilya \\ Vishvavidyalaya, Indore, MP, India.
}

\begin{abstract}
Today there are numerous challenges are being faced by Indian construction managers. Some are new to the industry, and some are centuries old. Many of these challenges are a direct result of construction operations, while others a result of indirect, peripheral activities. A surprising number of challenges are not construction issues but must be addressed and managed by the construction manager (CM) to ensure project success. Some of the construction issues include workforce considerations, safety, time constraints, and the changing nature of the work. Non-construction challenges that CMs face that are part of the business landscape include legal issues, government regulations, environmentalconcerns, and socio-political pressures. It is critical that the CM understands thedemanding realities that he or she faces in the planning and control of constructionoperations.
\end{abstract}

\section{Introduction}

Construction projects represent a unique set of activities that must take place to produce a unique product. The success of a project is judged by meeting the criteria of cost, time, safety, resource allocation, and quality as determined by the owner. The purpose of Project Management is to achieve goals and objectives through the planned expenditure of resources that meet the project's quality, cost, time, scope, and safety requirements. The CM must control, deflect, or mitigate the effects of any occurrence or situation that could affect project success.

\section{Nature Of The Work}

Construction is a complex array of interdependent activities that some would say is at bestorganized chaos. The very nature of construction introduces challenges [1]. typically notencountered in other industries. For example, construction differs widely from manufacturing in that: the work is often seasonal, each project is unique, often involves remote sites with various access problems, the process is not as predictable, difficulty in applying automation, there is high potential for encountering unforeseen conditions, costs can vary according to conditions, difficult to manage and supply utilities and other resources, - technical innovations are adopted slower, success is dependent upon the quality of its people, very custom-oriented, product can be of mindboggling size, cost, and complexity, the work is not performed in controlled conditions, therefore highly impacted by weather and other environmental conditions .

Weather and construction have been at odds since the beginning. Today's meteorologists have a vast array of tools such as Doppler radar, satellite, and computer modeling. These tools enable the meteorologist to predict weather patterns and events with some degree of accuracy. However, even with the most sophisticated technology available, forecasts are still subject to wide variability and questionable accuracy. Even ifmeteorologists could predict weather to a degree of accuracy of $\pm 5 \%$, the impending weather events cannot be modified or delayed. The construction manager remains at the mercy of the weather. This fact is particularly troublesome to those engaged in heavy civilwork, site development, and activities that involve earthwork or other weather sensitiveoperations. Those located in northern climates often have limited construction seasons. Weather related delays or curtailments are especially unwelcome in today's highly time driven construction environment. Weather is one of many variables that the CM cannot control. The CM must recognize the impact of weather and mitigate the effects whenever possible. The nature of the work is changing to include more retrofit, rehabilitation, and restoration (RRR) along with new work[2]. RRR work introduces greater risk into the process. These risks include limited or non-existent as-built information, maintaining existing facilities during construction, and the various other difficulties associated with marrying new work to old. Work in urban settings is further complicated by the growing presence of utilities that must be maintained and protected through the course of construction. Damages accrued from the interruption of services such as communications can be very costly, to the point of bankrupting the constructor. Construction work rarely occurs in isolation. The surrounding built environment must be safely maintained and preserved during construction. 


\section{Work Force Considerations}

As is the case in any business, people are a construction organization's greatest resource. Construction operations depend on the knowledge and skills of people planning and executing the work. The quality of this most important resource: people, is what distinguishes one team or company from another. Having talented management in place to guide and direct operations is crucial. Obviously, having an adequate number of skilled and unskilled workers to perform the work is a bare necessity. Finding and recruiting sufficient numbers of skilled, talented people is becoming increasing difficult. There are several factors contributing to this problem. Construction is typically viewed as being one of the least desirable industries in which to work. Surveys among the nation's youth show construction at the bottom of the list of professions that they would enter. Construction by nature is dangerous, dirty, hard work. Other industries or professions offer preferred work environments that are cleaner, safer, and generally more desirable. The pervasive growth of technology and the associated industries that have followed are attracting the youth away from traditional industries. Consequently, there is a severe shortage of bright, talented people willing to work in construction.

The construction industry in North America has relied upon immigrant or foreign labor to varying degrees through the course of history[3]. Thousands of Chinese laborers built the transcontinental railroads in the 19th century. European immigrants constructed the urban landscape in the 19th and 20th centuries. Today, the labor void is being filled largely by Hispanics. Hispanic labor from Mexico and other Latin American countries is filling the gap in the domestic workforce. These hard working individuals are making a substantial contribution toward keeping the industry moving and producing. There are however, complications involved with employing a foreign workforce, namely language and cultural barriers. The obvious problems in communication can lead to confusion that can hamper productivity and coordination. The language barrier also imposes additional safety risks. Construction managers need to provide solutions to enhance productivity and ensure safety among the Hispanic workers. In order to maximize long-term performance, it is important to provide the Hispanic worker with the training necessary to hasten the assimilation into the U.S. workforce. Leadership must be raised from among the Hispanic workers to aid in effectively coordinating work activities by providing the communication link between management and work crews. This provides the opportunity for upward mobility and gives motivated individuals the chance to advance professionally. Empowerment leads to high levels of commitment, enthusiasm, self-motivation, productivity, and innovation. Benefits to the employee include feelings of appreciation, belonging, and heightened self-worth which motivates them.

Empowerment enables employees to make decisions for which they are accountable and responsible. Research indicates the level of empowerment does influence productivity. A high level of empowerment yields correspondingly higher productivity. Empowerment of the workforce is one of the keys to improving construction performance.

\section{Safety}

Safety remains an on going concern for the construction manager. Construction by nature is inherently dangerous, with a high degree of hazard and risk. The toll of construction accidents is high in terms of both costs and human suffering. Accidents add a tremendous burden of needless and avoidable expense. Financial loses pale when compared to bodily injury and death, and the resulting human, social impacts. protects the contractor from certain direct expenses, but accidents also involve substantial costs that are not insurable, referred to as hidden or indirect cost. Direct costs include medical cost and compensation. Indirect or hidden costsinclude:

- time lost from work by the injured party

- loss in earning power, economic loss to injured worker's family

- diminished quality of life for the injured party

- loss of efficiency by breaking up crew

- cost to train new or replacement employees

- damage to equipment and tools

- loss of production

- cost incurred by delays

- failure to meet contract demands (completion, etc)

- overhead costs associated with disruption of work

- cleanup and repair costs

- administrative costs of investigations and reports

- increased insurance premiums

- loss of future projects due to adverse publicity

- cost of fines

- many, many others difficult to quantify

The CM must be concerned with the issues of safety for several reasons including: 
Legal obligations imposed by OSHA, Contract requirements, Direct and indirect financial impact (profit picture), Corporate \& personal legal liability (fiduciary duty), Ethical duty and moral obligation, Public image and reputation

The courts charge the employer (management) with the responsibility of providing a safe place to work; safe appliances, tools, and equipment; developing and enforcing safety rules and regulations; and providing instructions regarding employment dangers. Keys to a successful construction safety program includes[3]: support and enforcement from top management, front line management (superintendents \& foremen) consistently following and enforcing the safety program, on-going and comprehensive training, and recognition by all employees that safety is everyone's job.

\section{Time Constraints}

Time is money to owners, builders, and users of the constructed facility. From the owner's perspective there is lost revenue by not receiving return on investment, cash flow crunch, potential alienation and loss of clients/tenants, extended interest payments, and negative marketing impacts. From the users' perspective, there are financial implications similar to owners. Delays in upgrading facilities translate into operating at below optimum efficiency resulting in higher user cost. Delays in constructing or rehabilitating infrastructure negatively affects businesses and the public at-large. Time implications from the constructor's perspective include liquidated damages (negative) and incentive/disincentive payments. Delays result in extended overhead costs and puts a crunch on critical cash flow. Extending project durations limits the constructor's bonding capacity and ability to bid more work (opportunity cost). Inefficient time management results in higher labor and equipment costs. A reputation for late completions is bad for business, especially in negotiated work. In today's intensely time driven business environment, superior planning, scheduling, and control are vital. The $\mathrm{CM}$ is faced with the challenges of completing high volumes of work within tight time frames, and generally finite resources. CMs must comprehensively plan construction operations and closely monitor progress. CPM schedules and linear schedules are valuable tools that provide several advantages in managing construction operations. Schedule preparation requires managers to think the project through prior starting the work and provides a structured approach to planning. Comprehensive schedules provide a means of communicating the work plan to others. Schedules must be an accurate portrayal of the work plan to realize the full value. A good, regularly updated schedule in the hands of a competent CM is a powerful tool. Good schedules are critical to project success; however, they are only a tool. Schedules do not build things; people build things. Proactive rather than reactive control by the CM is a key to staying on schedule. Events or conditions that cause delays and require appropriate action include weather, lower productivity than anticipated, delivery problems, resource constraints, changes in scope, and differing site conditions. The CM must manage or mitigate these situations in order to deliver a constructed project on time. Time is of the essence!

\section{Environmental Issues}

The impact of environmental issues on construction has been escalating since the 1970's. Today, owners and constructors are bound to clearly defined duties and liabilities regarding the environment[4 ]. Nearly all segments and sectors of the industry are affected by one or more environmental issues. Strict regulation, permitting requirements, and enforcement are designed to protect human health and the natural environment. Failure to comply with environmental regulation can result in project delay or termination, disqualification from future work opportunities, fines, civil action, and even criminal prosecution. It is paramount that CMs have full knowledge and understanding of environmental regulations and permit requirements. Major Federal regulations that apply to construction activities include the Federal Water Pollution Control Act (Clean Water Act), Clean Air Act, Resource Conservation and Recovery Act, and the Comprehensive Environmental Response Compensation and Liability Act. Individual states, counties, and municipalities have laws that supplement or are even more stringent than the Federal regulations. It is important that owners recognize their cradle-to-grave responsibilities.

Environmental concerns that impact construction include erosion and sedimentation control, wetlands and parklands, leaking underground storage tanks and contaminated soil, lead paint removal, asbestos, hazardous waste, dust control, and noise. All of these concerns increase the organization's risk, which the CM must address and effectively manage. Ignorance of the law is no excuse and can place the project, owner, constructor, and CM in jeopardy.

\section{Legal Issues}

The United States has become a highly litigious society[5]. The number of civil actions is growing at an alarming rate. Businesses across the board are at great risk because of liability and other legal implications. Not many industries are exposed to greater risks from legal issues than the construction industry. Construction business is conducted through contractual arrangements that at times results in disputes. Claims and disputes 
have been steadily on the rise for years. A claim is a request by a contractor for additional compensation or time extension for occurrences beyond the contractor's control. The contractor must prove entitlement and quantify the associated damages. Timely notice of claim upon discovering impact is required. The owner has a duty to provide adequate, accurate data to the bidders, and is liable to the constructor when inaccurate data are given, extras develop because of improper design, or the design is significantly changed after the contract is signed (constructive change). Change in scope and differing or unexpected site conditions are grounds for a claim. The various types of claims include delay/disruption, extra work claims, acceleration, impossibility-of-performance, defective design (error or omission), interference, and superior knowledge claims. The industry continues to seek less adversarial methods of resolving disputes and settling claims. The motivation is to reduce costs by equitably resolving issues before they escalate into litigation. Alternative dispute resolution (ADR) practices have been employed with some success. ADR methods include negotiation, arbitration, mediation, neutral advisors, and Dispute Review Boards (DRB). ADR has demonstrated great value in resolving issues to the satisfaction of both parties. However, in some cases litigation is unavoidable. It is usually undesirable, but sometimes the best method for final resolution. Claims in general are bad for the industry. All parties must work to reduce the frequency and magnitude of claims. The $\mathrm{CM}$ plays a central role in claims avoidance and resolution. Claims avoidance begins in the pre-construction phase; a time with the greatest potential to influence cost. A large percentage of claims could be avoided by generating comprehensive, accurate, contract documents. Preconstruction claims avoidance requires intensive document and constructability reviews. Careful consideration should be given to the construction means and methods during the design phase. Designs should allow construction using the prevailing methods and equipment, specify a level of workmanship consistent with the quality of the project, and not require the constructor to assume responsibility for information that should be furnished by the designer Specifications should be simple and straightforward, clearly stating what is expected. $\mathrm{CM}$ input during preconstruction reviews is invaluable. The constructor must have a clear understanding of contract requirements prior to bidding. Keys to avoiding claims during construction include good administrative procedures, open and honest communication, and timely troubleshooting.

\section{Governmental Regulation}

Increasing government regulation is another of the challenges facing today's CM. Along with increasing environmental and safety laws, the industry is coming under greater regulation through the construction codes and licensing requirements. State and local municipalities adopt model codes such as the Basic/National Building Code (BOCA Code) Uniform Building Code (UBC), or the Standard Building Code (SBC). The International Building Code 2000 (IBC) now replaces the first three codes. Other important model codes include the National Electric Code (NEC) and Life Safety Code by the NFPA under ANSI. These codes provide for public safety by establishing minimum construction standards for structural integrity and fire safety. Local building codes are based on one of the model codes, but often include modifications that are unnecessarily restrictive. Some local codes are outdated and obsolete and prohibit the use of often superior, cost-effective materials and systems. Permitting requirements, contractor licensing laws, and the associated cost are also escalating. Quality of code administration is also a concern as are the delays caused by waiting for inspection. Public works projects that receive Federal or State funds are also subject greater process and administrative regulation. Timely resolution of issues is often entangled in bureaucratic red tape.

\section{Socio-Political Pressures}

Socio-Political pressures have more impact on construction than in the past[6]. Political pressures and community involvement affect public and to some extent, private sector work. Pressures emanate from adjacent property owners and the public at-large, including existing businesses, institutions, and residences adjacent to the constructed facility. Civic organizations and community groups have more input into design and construction of public works projects, and greater impact on private work through the land use and planning process. The community has greater input through citizen advisory boards that are engaged during project initiation, design, and construction. Today's CM has substantially greater accountability to the public than previous generations. Increasing the number of stakeholders further complicates an already complex process. Socio-political pressures also stem from the NIMBY syndrome (not in my back yard). The NIMBY syndrome stymies growth and development, and generally hampers construction. The obstacles caused by the NIMBY syndrome typify the challenges facing today's CM.

\section{Conclusion}

Today's CM faces many challenges, stemming from a variety of sources. These challenges can have an impact on project success. CMs must be keenly aware of the risks and implications of these challenges. The challenges listed in this report include situations and conditions that must be proactively managed by the CM to ensure project success. Many of these challenges are a direct result of construction operations, while others are 
result of indirect, peripheral activities. Construction issues include workforce considerations, safety, time constraints, and the changing nature of the work itself. Non construction challenges that CMs face that are part of the business landscape include legal issues, government regulations, environmental concerns, and sociopolitical pressures. Excellent CMs understand and navigate through these realities. CMs that are able to master obstacles gain a competitive advantage. Excellent CMs transform risks into opportunities. Excellent CMs understand the business, legal and social aspects of construction. They act as responsible stewards of the environment and observe all applicable laws and ethical practices. Excellent CMs value the people they employ and work to ensure their safety and promote their well-being. Excellent CMs proactively manage operations to achieve the project's quality, cost, time, and scope requirements. The excellent CM strives to avoid and resolve conflict and promote harmony among all project stakeholders. The excellent CM adapts to the changing business, social, and legal environment, and leads the organization through the challenges it faces.

\section{References}

[1] Barrie, S., Donald, and Boyd C. Paulson, Professional Construction Management: including CM, Design-Construct, and General Contracting, (3rd edition, New York: McGraw-Hill, 1992).

[2] Bockrath, T., Joseph, Dunham and Young's Contracts, (Specifications, and Law for Engineers, 4th edition, New York: McGraw-Hill, 1986).

[3] Clough, H., Richard, Construction Contracting, (New York: John Wiley \& Sons, 1986).

[4] Hinze, W., Jimmie, Construction Planning and Scheduling, (2nd edition, Upper Saddle River,New Jersey: Pearson Prentice Hall, 2004).

[5] Nunnally, S. W., Construction Methods and Management, (6th edition, Upper Saddle River,New Jersey: Prentice-Hall, 2004).

[6] O'Brien, James J. and Robert G. Zilly, Contractor's Management Handbook, (2nd edition,New York, McGraw-Hill: 1991). 